\title{
SEROTYPES AND ANTIMICROBIAL SUSCEPTIBILITY OF INVASIVE STREPTOCOCCUS PNEUMONIAE ISOLATED IN SERBIA IN 2012-2013
}

SEROTIPOVI I ANTIMIKROBNA OSETLJIVOST
INVAZIVNIH SOJEVA STREPTOCOCCUS PNEUMONIAE
IZOLOVANIH U SRBIJI OD 2012 DO 2013. GODINE

Ina Gajić , Miloš Marković, Dušan Kekić1, Sunčica Popović, Vera Mijač ' Lazar Ranin', Nataša Opavski

\section{Summary}

The aim of this study was to: determine susceptibility patterns of invasive Streptococcus pneumoniae to antimicrobial agents, evaluate macrolide resistance phenotypes and genotypes and identify capsular serotypes among invasive isolates of $S$. pneumoniae circulating in Serbia.

The total of 85 invasive pneumococcal strains, collected during 2012 and 2013, were sent from regional laboratories to the National Reference Laboratory. Susceptibility testing was performed by disk diffusion and $\mathrm{E}$ test, while phenotypes and genotypes of macrolide resistant strains were determined by double-test and PCR, respectively. Serotyping was performed by Quelling reaction.

The overall penicillin and erythromycin non-susceptibility rates were $14.12 \%$ and $28.23 \%$, respectively. Resistance rates were significantly higher in children than in adults and $(p<0,01)$. Co-resistance to penicillin and erythromycin was detected in $7.06 \%$ strains. Resistance rates to tetracycline and chloramphenicol were $29.41 \%$ and $15.29 \%$, respectively. The rate of multiresistance was $27.06 \%$. cMLS phenotype was detected in $62.5 \%$ of all macrolide resistant isolates, while $37.5 \%$ expressed M phenotype. All 15 isolates with CMLS phenotype harbored ermB gene and all M isolates harbored mefA. The most common resistant serotypes were 3,9A and 23F.

This study revealed that penicillin and macrolide resistance among invasive pneumococcal isolates is high. Obtained results emphasize the need for continuous monitoring of invasive pneumococcal disease in Serbia.

Key words: Streptococcus pneumoniae, invasive pneumococcal disease, serotypes, macrolide resistance, resistant genes

\section{Sažetak}

Cilj ovog istraživanja je bio da se ispita osetljivost invazivnih sojeva S. pneumoniae na antimikrobne agense, da se odrede fenotipovi i genotipovi rezistencije na makrolide, kao i da se identifikuju serotipovi invazivnih cirkulišućih sojeva pneumokoka.

Istraživanje je obuhvatilo invazivne sojeve Streptococcus pneumoniae izolovane u periodu od 2012. do 2013. godine koji su iz regionalnih laboratorija poslati u Nacionalnu referentnu laboratoriju za streptokok. Disk difuzionom metodom i E testom je ispitana osetljivost 85 izolata S. pneumoniae na antibakterijske agense, fenotipovi rezistencije na makrolide određeni su "D" testom, a geni koji determinišu rezistenciju na makrolide metodom PCR. Kapsularna tipizacija je izvršena reakcijom bubrenja kapsule.

Rezistencija na penicillin je uočena kod 14,12\% sojeva, a rezistencija na eritromicin kod 28,23\%. Učestalost rezistencije S. pneumoniae na beta laktamske antibiotike i eritromicin je bila značajno viša kod decijijh izolata nego kod sojeva izolovanih od odraslih pacijenata $(p<0,01)$. Korezistencija na penicillin i eritromicin je detektovana kod 7,06\% izolata. Rezistencija na tetraciklin je bila 29,41\%, a na hloramfenikol $15,29 \%$. Procenat multirezistentnih sojeva je bio 27,06\%. Dominantan fenotip rezistencije na makrolide je bio CMLS, koji je bio uočen kod 62.5\% izolata rezistentnih na makrolide. M fenotip je bio detektovan kod 37,5\% sojeva. Svi sojevi sa cMLS fenotipom su imali ermB gen, a svi izolati sa M fenotipom mefA gen. Tri soja sa cMLS fenotipom su istovremeno imali oba gena. Najěěći rezistentni serotipovi su bili 3, 9A i $23 \mathrm{~F}$.

Rezultati studije pokazali su da je rezistencija invazivnih pneumokoka na peniclin i makrolide veoma visoka u ispitivanoj kolekciji sojeva. Među rezistentnim sojevima dominantni su serotipovi 14 i 19F. Dobijeni rezultati ukazuju na potrebu za kontinuiranim monitoringom invazivnih pneumokoknih bolesti.

Ključne reči: Streptococcus pneumoniae, invazivna pneumokokna bolest, serotipovi rezistencija na makrolide, geni

\section{UvoD}

Streptococcus pneumoniae (pneumokok) može biti deo fiziološke mikroflore nazofaringsa, ali i izazivač brojnih invazivnih i neinvazivnih infekcija. Jedan je od najznačajnijih humanih patogen, ali i vodeći uzročnik bakterijskog meningitisa i sepse širom sveta. Invazivna pneumokokna bolest (IPB) je klinički potvrđena i laboratorijski dokazana izolacijom Streptococcus pneumoniae iz primarno sterilnih regija (krv, likvor, zglobna šupljina) (1). Osobe starije od 65 godina, deca mlađa od 2 godine i splenektomisane osobe imaju povećan rizik da obole od IPB.

Povećana učestalost rezistencije pneumokoka na antibakterijske agense predstavlja problem svetskih razmera (2). Povećanje učestalosti rezistencije $S$. pneumoniae na beta-laktamske antibiotike i makrolide uočeno je u brojnim zemljama širom sveta, posebno u periodu pre uvođenja vakcine protiv pneumokoka u nacionalne imunizacione programe (3). 
Dva su glavna mehanizma rezistencije pneumokoka na makrolide: modifikacija ciljnog mesta delovanja leka i aktivni efluks antibiotika. Modifikaciju ciljnog mesta vrši enzim metilaza, koju kodiraju ermA i ermB geni (erm erythromycin ribosome methylase). Metilacija ribozoma dovodi do ukrštene rezistencije na 14-, 15- i 16-očlane makrolide, na linkozamide i streptogramin B (MLS antibiotici). Ovaj tip rezistencije je označen kao MLS fenotip. MLS fenotip rezistencije može biti konstitutivan (cMLS) i inducibilan (iMLS). Inducibilni fenotipovi ispoljavaju rezistenciju na klindamicin i streptogramin samo u prisustvu induktora, dok se cMLS fenotip karakteriše visokim nivoom rezistencije na makrolide i na linkozamide $(\mathrm{MIK} \geq 264 \mathrm{mg} / \mathrm{L})$. Aktivni efluks antibiotika je posredovan efluks pumpama, koje kodira mefA gen. Ovaj mehanizam rezistencije se ispoljava kao $\mathrm{M}$ fenotip i karakteriše se rezistencijom samo na 14- i 15-očlane makrolide ali ne i na 16-očlane makrolide, linkozamide i streptogramin.

Sposobnost pneumokoka da horizontalnim transferom razmenjuje genski materijal pomaže sojevima da se adaptiraju na promene u okruženju i razviju rezistenciju na dejstvo antibiotika, što dovodi do genetičke raznovrsnosti izolata (4).

Do sada su identifikovana 93 serotipa pneumokoka, koji se međusobno razlikuju po strukturi polisaharida koji se nalazi u kapsuli. Klinički spektar infekcija, koje izaziva pneumokok, najviše zavisi od kapsularnog serotipa. Serotipovi 1, 4, 5, 7F, 8, 12F, 14, 18C i 19A najčešće uzrokuju IPB.
Postoje dva tipa vakcina protiv pneumokoknih infekcija koje su u kliničkoj upotrebi: polivalentna polisaharidna vakcina (PPSV) i polivalentne konjugovane vakcine (PCV) koje sadrže pneumokokne Ag najznačajnijih serotipova. Kod konjugovanih vakcina kapsularni polisaharidi su konjugovani sa visoko imunogenim nepneumokoknim proteinskim nosačem. Polisaharidna vakcina nije dovoljno imunogena kod dece mlađe od 2 godine, pa se kod njih primenjuje neka od PCV.

Cilj istraživanja je bio da se identifikuju odredi antimikrobna osetljivost invazivnih izolata $S$. pneumoniae izolovanih u Srbiji tokom perioda 2012-2013. godine, da se odrede fenotipovi i genotipovi rezstencije na makrolide, kao i da se identifikuju cirkulišući serotipovi

\section{MATERIJAL I METODE}

Istraživanje je obuhvatilo 85 invazivnih sojeva $S$. pneumoniae izolovanih od pacijenata iz Srbije tokom 2012. i 2013. godine. Broj pedjatrijskih sojeva ( $<16$ godina) je 27 , dok je broj adultnih izolata 58. Sojevi su izolovani i identifikovani u regionalnim mikrobiološkim laboratorijama i slati su u Nacionalnu referentnu laboratoriju za streptokok, radi dalje obrade.

Sojevi su izolovani iz krvi ( $\mathrm{N}=44)$, likvora $(\mathrm{N}=28)$, pleuralnih punktata $(\mathrm{N}=12)$ i brisa abdominalne duplje $(\mathrm{N}=1)$.

Tabela 1: Osetljivost invazivnih izolata Streptococcus pneumoniae na antibiotike

\begin{tabular}{|c|c|c|c|c|c|c|}
\hline \multirow{3}{*}{$\begin{array}{l}\text { Antibiotik } \\
\text { Tetraciklin }\end{array}$} & \multicolumn{6}{|c|}{ Kategorije osetljivosti } \\
\hline & \multicolumn{2}{|c|}{$\begin{array}{l}\text { Osetljiv (S) } \\
\quad \text { N (\%) }\end{array}$} & \multicolumn{2}{|c|}{$\begin{array}{c}\text { Intermedijarno osetljiv (I) } \\
\mathrm{N}(\%)\end{array}$} & \multicolumn{2}{|c|}{$\begin{array}{l}\text { Rezistentan (R) } \\
\text { N (\%) }\end{array}$} \\
\hline & 58 & $(68,24)$ & 2 & $(2,35)$ & 25 & $(29,41)$ \\
\hline Hloramfenikol & 72 & $(84,7)$ & 0 & (0) & 13 & $(15,29)$ \\
\hline Ofloksacin & 82 & $(96,47)$ & 3 & $(3,53)$ & 0 & (0) \\
\hline
\end{tabular}

Tabela 2: Fenotipovi rezistencije na makrolide, genetske determinante i minimalne inhibitorne koncentracije eritromicina i klindamicina invazivnih izolata Streptococcus pneumoniae rezistentnih na makrolide

\begin{tabular}{|c|c|c|c|c|c|c|c|}
\hline \multirow[t]{2}{*}{$\begin{array}{l}\text { Fenotip rezistencije } \\
\text { na makrolide }\end{array}$} & \multirow[t]{2}{*}{$\begin{array}{l}\text { Broj izolata } \\
\quad \text { N (\%) }\end{array}$} & \multicolumn{2}{|c|}{$\begin{array}{c}\text { Geni } \\
\mathrm{N}\end{array}$} & \multirow[t]{2}{*}{ Antibiotik } & \multicolumn{3}{|c|}{ MIK ( $\mu \mathrm{g} / \mathrm{ml})$} \\
\hline & & mefA & ermB & & $50 \%$ & $90 \%$ & rang \\
\hline $\mathbf{M}$ & $4(5,13)$ & 4 & 0 & $\begin{array}{l}\text { eritromicin } \\
\text { klindamicin }\end{array}$ & $\begin{array}{c}6 \\
0,047\end{array}$ & $\begin{array}{c}16 \\
0,094\end{array}$ & $\begin{array}{c}2-16 \\
0,032-0,094\end{array}$ \\
\hline cMLS & $6(7,69)$ & 3 & 7 & $\begin{array}{l}\text { eritromicin } \\
\text { klindamicin }\end{array}$ & $\begin{array}{l}>256 \\
>256\end{array}$ & $\begin{array}{l}>256 \\
>256\end{array}$ & $\begin{array}{l}>256 \\
>256\end{array}$ \\
\hline
\end{tabular}

Tabela 3. Povezanost serotipova Streptococcus pneumoniae i rezistencije na antibakterijske agense

\begin{tabular}{lccc} 
& $\begin{array}{c}\text { Udružena rezistencija na } \\
\text { penicillin i eritromicin }\end{array}$ & Rezistencija na tetraciklin & Multirezistencija \\
Serotipovi: & $14,23 \mathrm{~F}$ & $3,6 \mathrm{~B}, 9 \mathrm{~A}, 9 \mathrm{~V}, 9 \mathrm{~N}, 12 \mathrm{~F}, 14,15 \mathrm{~B}, 19 \mathrm{~F}$, & $3,9 \mathrm{~A}, 23 \mathrm{~F}$ \\
& & $22 \mathrm{~F}, 23 \mathrm{~F}$ & $23(27.06)$ \\
\hline
\end{tabular}


Prekonoćna kultura pneumokoka je suspendovana u moždano srčani bujon (Biolife, Italija) i inkubirana na $36{ }^{\circ} \mathrm{C}$, u atmosferi sa $5 \% \mathrm{CO}_{2}, 20 \mathrm{~h}$. Sojevi su konzervirani na $-80^{\circ} \mathrm{C}$. Identifikacija pneumokoka je izvršena na osnovu analize kulturelnih osobina, bojenja po Gramu, osetljivosti na optohin (BioRad, SAD), hidrolize žuči i reakcije aglutinacije (Pneumo-kit slidex test, bioMérieux, Francuska). Ispitivanje osetljivosti na penicilin (10IU), ceftriakson $(30 \mu \mathrm{g})$, eritromicin $(15 \mu \mathrm{g})$, klindamicin $(2 \mu \mathrm{g})$, tetraciklin $(30 \mu \mathrm{g})$, hloramfenikol $(30 \mu \mathrm{g})$ i norfloksacin $(10 \mu \mathrm{g})$ (BioRad, SAD) je vršeno disk difuzionom metodom antibiograma, dok je osetljivost na penicilin, eritromicin i klindamicin testirana i E testom, prema preporukama Evropskog komiteta za testiranje antimikrobne osetljivosti (engl. The European Committee on Antimicrobial Susceptibility Testing, EUCAST) (5).

Sojevima koji su pokazali smanjenu osetljivost na eritromicin su određeni fenotipovi rezistencije na makrolide dvostrukim disk difuzionim testom. Na zasejanu Mueller Hinton podlogu sa dodatkom 5\% krvi aplikovani su diskovi eritromicina i klindamicina na udaljenosti od $15-20 \mathrm{~mm}$. Test je očitavan nakon inkubacije na $36{ }^{\circ} \mathrm{C}$, $\mathrm{u}$ atmosferi sa $5 \% \mathrm{CO}_{2}, 20 \mathrm{~h}$. Sojevi rezistentni na eritromicin i osetljivi na klindamicin su imali $\mathrm{M}$ fenotip, sojevi bez zone inhibicije rasta oko eritromicina i sa tzv. D zonom inhibicije rasta oko klindamicina su pripadali iMLS fenotipu, a odsustvo zona inhibicije rasta oko oba antibiotika je odgovaralo cMLS fenotipu. (6) Kod sojeva rezistentnih na makrolide, određivani su i geni koji determinišu makrolidnu rezistenciju, reakcijom lančanog umnožavanja (eng. polymerase chain reaction, PCR), prema protokolu Farela i saradnika (7).

Serotipizacija je urađena reakcijom bubrenja kapsule sa serogrupnim i serotipskim antitelima na kapsularne polisaharide (Statens Serum Institute, Kopenhagen, Danska) (8).

Podaci su obrađeni metodama deskriptivne statistike, a za procenu značajnosti korišćen je hi-kvadrat test. Statistički značajnom razlikom (SZR), smatralo se $0,01<p<0,05$, a visokom statističkom značajnošću (VSZR), $p<0,01$.

\section{Rezultati}

OSETLJIVOST SOJEVA NA ANTIBAKTERIJSKE AGENSE

Od ukupno 85 ispitivanih sojeva pneumokoka, 66 sojeva $(77,6 \%)$ je bilo osetljivo na penicilin, dok je 19 izolata $(22,4 \%)$ pokazalo smanjenu osetljivost na penicilin, a 12 $(14,12 \%)$ sojeva je bilo rezistentno na penicilin. Od 28 sojeva pneumokoka izolovanih iz likvora, 11 je bilo rezistentno na penicillin (39,3\%), dok je od preostalih 57 nemeningealnih izolata, samo 1 bio rezistentan $(1,8 \%)$.
Uočena je visoko značajna statistička razlika u procentualnoj zastupljenosti rezistencije na penicillin, kod meningealnih i nemeningealnih sojeva $(\mathrm{p}<0,01)$.

Većina ispitivanih izolata $S$. pneumoniae, ukupno 71 $(84,06 \%)$ je bilo je osetljivo na ceftriakson, dok je smanjenu osetljivost na ceftriakson pokazalo svega 14 sojeva $(15,94 \%)$.

Pedeset osam sojeva $(68,24 \%)$ je bilo osetljivo na eritromicin, dok je 27 izolata $(31,76 \%)$ imalo smanjenu osetljivost na eritromicin, od čega je 1 soj $(1,17 \%)$ bio intermedijarno osetljiv, a 26 sojeva $(30,59 \%)$ rezistentno na eritromicin.

Osetljivost invazivnih izolata pneumokoka na ostale antibiotike je prikazana u Tabeli 1.

\section{FENOTIPOVI I GENOTIPOVI REZISTENCIJE NA MAKROLIDE}

cMLS fenotip je bio dominantan kod ispitivanih izolata $S$. pneumoniae i bio je prisutan kod 15 od 24 sojeva $(62,5 \%)$ rezistentnih na makrolide, dok je $\mathrm{M}$ fenotip bio zastupljen kod samo 9 od 24 sojeva (37,5\%). iMLS fenotip nije bio detektovan ni kod jednog soja $S$. pneumoniae (Tabela 2). Minimalne inhibitorne koncentracije (MIK) eritromicina i klindamicina sojeva rezistentnih na makrolide, prikazane su takođe u tabeli 2. Svi sojevi sa M fenotipom su imali mefA gen, a svi sojevi sa cMLS fenotipom ermB gen, pri čemu su 3 soja sa cMLS fenotipom imali istovremeno i mefA gen (Tabela 2).

\section{SEROTIPOVI INVAZIVNIH IZOLATA STREPTOCOCCUS PNEUMONIAE}

U našem istraživanju je identifikovano ukupno 19 pneumokoknih serotipova. Najčešći serotip je bio serotip 3 i on je bio zastupljen kod 22,54\% izolata. Ostali identifikovani serotipovi su bili: 7F (8,45\%), 14 (8,45\%), 19F (8,45\%), 4 (7,03\%), 23F (7,03\%), 8 (5,63\%), 9V (5,63\%), $6 \mathrm{~A}(4,23 \%), 9 \mathrm{~N}(4,23 \%), 12 \mathrm{~F}(4,23 \%), 9 \mathrm{~A}(2,82 \%), 22 \mathrm{~F}$ $(2,82 \%), 5(1,41 \%), 6 \mathrm{~B}(1,41 \%), 15 \mathrm{~B}(1,41 \%), 17 \mathrm{~F}(1,41 \%)$, $18 \mathrm{C}(1,41 \%), 19 \mathrm{~A}(1,41 \%)$.

Kod dece, starosti do 16 godina, izolovani su sledeći serotipovi: 3, 5, 6A, 6B, 7F, 9A, 14, 19F, 23F, 33, pri čemu su najčešći bili $14(12,5 \%)$ i $23 \mathrm{~F}(16,67 \%)$. Kod sojeva izolovanih od odraslih pacijenata identifikovani su sledeći serotipovi: $3,4,6 \mathrm{~A}, 7 \mathrm{~F}, 8,9 \mathrm{~A}, 9 \mathrm{~V}, 9 \mathrm{~N}, 12 \mathrm{~F}, 14,15 \mathrm{~B}$, 17F, 18C, 19A, 19F, 22F, 23F, pri čemu su najčešći bili 3 (22,95\%), 8 (6,6\%), 14 (4,91\%), 19F (4,91\%).

Izolati S. pneumoniae koji su bili rezistentni na penicilin su imali serotipove 3, 9A, 9N, 12F, 14, 19F, 23F, pri čemu su najzastupljeniji bili serotipovi 14 i 19F. Isti serotipovi 
su bili dominantni i kod sojeva rezistentnih na eritromicin. Serotipovi S. pneumoniae identifikovani kod izolata rezistentnih na tetraciklin, udruženo rezistentnih na penicilin i eritromicin, kao i kod multiplo reyistentnih sojeva su prikayani u tabeli 3 . Svi sojevi serotipova 14 i 19F su imali cMLS fenotip rezistencije na makrolide i ermB gen.

\section{DiskUSIJA}

Rezultati naše studije pokazuju da je procentualna zastupljenost smanjene osetljivosti invazivnih izolata $S$. pneumoniae na penicilin $22,4 \%$, što predstavlja relativno visoku učestalost. Slične rezultate su objavili i autori iz Poljske (30\%), Rumunije (30\%) i Bugarske (37\%) (9), dok rezultati turskih autora ukazuju da je oko $50 \%$ izolata osetljivo na penicillin (10). U zemljama Mediterana, u kojima je vakcina protiv pneumokoka deo obaveynog imuniyacionog programa, u periodu pre uvođenja vakcine učestalost rezistencije invazivnih izolata $S$. pneumoniae bila visoka: 33\% u Španiji, 30\% u Italiji i 46\% u Francuskoj (11). Kod ispitivanih sojeva rezistencija na beta laktamske antibiotike je bila značajno češća kod dečijih nego kog sojeva izolovanih od odraslih pacijenata. I drugi autori navode da je rezistencija na penicilin učestalija kod pedijatrijskih izolata (12). Dobijeni rezultati se mogu objasniti i činjenicom da je većina meningealnih izolata bila izolovana od dece, a prema redigovanim kriterijumima za procenu osetljivosti pneumokoka na penicilin, razlikuju se granične vrednosti za meningealne, odnosno nemeningealne izolate (13). Učestalost rezistencije ispitivanih sojeva na makrolide je bila $28,23 \%$. Slične rezultate su objavili i autori iz Bugarske (27\%), dok su zastupljenosti u Mediteranskoj regiji u periodu pre uvođenja vakcine bile 55\% u Grčkoj, 54\% u Francuskoj, $42 \%$ u Italiji (11). S obzirom na to da je dokazano da je incidencija rezistencije streptokoka na makrolide u direktnoj korelaciji s potrošnjom ovih antibiotika (14), može se pretpostaviti da visokoj učestalosti rezistencije, kod sojeva izolovanih u populaciji u Srbiji, doprinosi nekritična upotreba makrolida, kao i njihova do skorašnja slobodna prodaja. Učestalost udružene rezistencije ispitivanih sojeva na penicilin i eritromicin je bila $21 \%$. Srbija pripada grupi zemalja sa najvišim nivoom kombinovane rezistencije pneumokoka u Evropi, zajedno sa Kiprom (27\%) i Rumunijom (25\%) (9). Invazivni izolati iz Srbije nisu pokazivali značajan stepen rezistencije na hloramfenikol i fluorohinolone.

Među 24 invazivna soja S. pneumoniae, koji su bili rezistentni na eritromicin, cMLS fenotip je bio uočen kod većine, odnosno kod 62,5\%. cMLS fenotip je dominantan u Italiji, Španiji i drugim zemljama Mediteranskog basena (14), dok M fenotip preovlađuje u Severnoj Americi, Velikoj Britaniji i Nemačkoj $(15,16)$.

Dominantni serotipovi kod sojeva rezistentnih na penicilin, eritromicin i tetraciklin su 14 i 19F. Ovakva epidemiološka slika je bila tipična za zemlje u periodu pre uvođenja konjugovane pneumokokne vakcine. Američki CDC (Centers for Disease Control and Prevention) je objavio da se u kategoriji sojeva pneumokoka rezistentnih na antibiotike u više od $90 \%$ slučajeva izoluju serotipovi: 6A, 6B, 9V, 14, 19A, 19F i 23F (1). Slična situacija je i u Evropi, a Imohl i saradnici su na osnovu podataka o rezistenciji invazivnih izolata pneumokoka na makrolide u Nemačkoj u periodu od 1992. do 2008. godine zaključili da su najviši nivoi rezistencije zabeleženi upravo kod serotipova 14, 6B, 19F i 23F (17). Ovi serotipovi su obuhvaćeni svim dostupnim konjugovanim vakcinama. Nakon uvođenja vakcine u nacionalne imunizacione programe epidemiološka situacija se izmenila i serotipovi 1 i 19A su dominantni u izazivanju invazivne pneumokokne pneumonije u većini evropskih zemalja, a serotip 14 jeste jedan od glavnih etioloških agenasa neinvazivne pneumonije odraslih (9).

Naša studija je pokazala da invazivni izolati S. pneumoniae imaju visok stepen rezistencije na beta laktamske antibiotike i eritromicin, posebno pedijatrijski izolati. Najčešći rezistentni serotipovi u svetu su takođe prepoznati i kod sojeva ispitivanih u ovoj studiji.

Zbog svega navedenog, u Srbiji bi trebalo započeti aktivni nadzor nad IPB.

\section{Literatura}

1. Centers for Disease control and preventions, CDC, 2010. Available on: http://www.cdc.gov/osels/ph_surveillance/nndss/casedef/IPD_current.htm.

2. Stephen GJ, Steven DB, David JF. Trends in antibacterial resistance among Streptococcus pneumoniae isolated in the USA: update from PROTEKT US Years 1-4. Ann Clin Microb Anti. 2008; 7:1.

3. Ramos-Sevillano E, Rodríguez-Sosa C, Díez-Martínez R, Giménez MJ, Olmedillas E, García P, García E, Aguilar L, Yuste J. Macrolides and $\beta$-Lactam Antibiotics Enhance C3b Deposition on the Surface of Multidrug-Resistant Streptococcus pneumoniae Strains by a LytA Autolysin-Dependent Mechanism. Antimicrob Agents Chemother. 2012; 56(11):5534-5540.

4. Song JY, Nahm MH, Moseley MA. Clinical Implications of Pneumococcal Serotypes: Invasive Disease Potential, Clinical Presentations, and Antibiotic Resistance. J Korean Med Sci. 2013; 28(1):4-15.
5. Catherine WO, Mark van der Linden, Iris de Schutter, Ron D, Lorenzo M. Prevention of pneumococcal diseases in the post-seven valent vaccine era: A European perspective. BMC Infect Dis. 2012; 12:207.

6. Montanari MP, Mingoia M, Giovanetti E, Varaldo PE. Differentiation of Resistance Phenotypes among Erythromycin-Resistant Pneumococci. J Clin Microbiol. 2001; 39:1311-1315.

7. Farrell DJ, Morrissey I, Bakker S, and Felmingham D. 2001. Detection of macrolide resistance mechanisms in Streptococcus pneumoniae and Streptococcus pyogenes using a multiplex rapid cycle PCR with microwell-format probe hybridization. J Antimicrob Chemoth. 2001; 48(4):541-4.

8. Sorensen UB. Typing of pneumococci by using 12 pooled antisera. J Clin Microbiol. 1993; 31, 2097-2100.

9. European Antimicrobial Resistance Surveillance Network, EARS, Annual report 2009. Dostupno na: http://ecdc.europa.eu/en/publications/ Publications/1011_SUR_annual_EARS_Net_2009.pdf 
10. Altun HU, Hascelik G, Gür D, Eser OK. Invasive pneumococci before the introduction of pneumococcal conjugate vaccine in Turkey: antimicrobial susceptibility, serotype distribution, and molecular identification of macrolide resistance. J Chemotherapy. 2015; 27(2):74-9.

11. European Antimicrobial Resistance Surveillance Network, EARS. Annual report 2001. Available from: http://www.ecdc.europa.

12. Kempf M, Baraduc R, Bonnabau H, Brun M, Chabanon G, Chardon H, Croizé J, Demachy MC, Donnio PY, Dupont P, Fosse T, Gibel L, Gravet A, Grignon B, Hadou T, Hamdad F, Joly-Guillou ML, Koeck JL, Maugein J, Péchinot A, Ploy MC, Raymond J, Ros A, Roussel-Delvallez M, Segonds C, Vergnaud M, Vernet-Garnier V, Lepoutre A, Gutmann L, Varon E, Lanotte P. Epidemiology and antimicrobial resistance of Streptococcus pneumoniae in France in 2007: data from the pneumococcus surveillance network. Microb Drug Resist. 2011; 17(1):31-6.

13. EUCAST, European Committee on Antimicrobial Susceptibility Testing. Breakpoint tables for interpretation of MICs and zone diameters. Version 2.0, January 2013.
14. Reinert RR, Reinert S, van der Linden M, Cil MY, Al-Lahham A, Appelbaum P. Antimicrobial Susceptibility of Streptococcus pneumoniae in Eight European Countries from 2001 to 2003. Antimicrob Agents Chemother. 2005; 49(7):2903-2913.

15. McEllistrem MC, Pass M, Elliott JA, Whitney CG, Harrison LH. Clonal Groups of Penicillin-Nonsusceptible Streptococcus pneumonia in Baltimore, Maryland: a Population-Based, Molecular Epidemiologic Study. J Clin Microbiol. 2000; 38(12):4367-4372.

16. Goossens H, Ferech M, Vander Stichele R, Elseviers M; ESAC Project Group. Outpatient antibiotic use in Europe and association with resistance: a cross-national database study. Lancet. 2005; 365(9459):579-87.

17. Imohl M, Reinert R, Ocklenburg C, van der Linden $M$. Association of serotypes of Streptococcus pneumoniae with age in invasive pneumococcal disease. J Clin Microbiol. 2010; 48(4):1291-6.

18. Scott TC, Xiaoliu Z, Dorothea Z, David SS. Induction of Efflux-Mediated Macrolide Resistance in Streptococcus pneumoniae. Antimicrob Agents Ch. 2011; 55(7): 3413-3422. 